\title{
Uma Proposta de Jogo Educacional para o Ensino e Aprendizagem de Geometria
}

\author{
Fabiana R. do Nascimento, Lucineide R. da Silva, \\ Karla J. Nonato, Nádson M. S. Silva, Luciano E. P. da Silva \\ Universidade Federal do Mato Grosso do Sul - Campus do Pantanal \\ Caixa Postal 79304-902 - Corumbá - Mato Grosso do Sul \\ \{fabiana.regis.nascimento, nadsonmatheus4\}@gmail.com \\ \{lucineide.silva, karla.nonato, luciano.silva\}@ufms.br
}

\begin{abstract}
This paper proposes an educational game for teaching and learning geometry for the first grade in elementary school. The content presented by the game is indicated on the core syllabus of the state of Mato Grosso do Sul, and aims to make the children to see the geometry discipline present in their daily lives in order to turn the learning task more enjoyable and fun.
\end{abstract}

Resumo. Este trabalho apresenta a proposta de um jogo educacional para o ensino e aprendizagem de geometria para crianças do $1^{\circ}$ ano do ensino fundamental. O conteúdo abordado no jogo é o indicado pelo Referencial Curricular do estado de Mato Grosso do Sul e busca fazer com que a criança enxergue a geometria presente em seu cotidiano de modo a tornar o aprendizado prazeroso e divertido.

\section{Introdução}

A utilização de jogos educacionais nas aulas pode ser bastante produtiva. [Tarouco et al. 2004] afirmam que o computador é uma ferramenta poderosa que deve ter todas as suas potencialidades utilizadas para educação, possibilitando que o professor utilize jogos educacionais e outros recursos que levem a uma aprendizagem prazerosa, divertida e acima de tudo motivadora.

Para [Bianchini et al. 2010] o ensino da matemática sempre foi muito trabalhoso, pois muitos alunos a enxergam como sendo uma disciplina rigorosa e formal, portanto complexa. Atualmente a geometria é uma matéria obrigatória na grade curricular de ensino, porém [Lorenzato 1995] afirma que no Brasil a geometria esteve ausente ou teve pouca presença nas salas de aula durante um longo período. $\mathrm{O}$ autor, destaca ainda que a geometria exige do aluno uma maneira específica de raciocinar, pensar, significando que mesmo um bom conhecimento de álgebra ou aritmética não é suficiente para resolver problemas relacionados a geometria.

Este artigo propõe um jogo educacional voltado ao ensino e aprendizagem de geometria para alunos do $1^{\circ}$ ano do ensino fundamental. O conteúdo abordado no jogo é o indicado pelo Referencial Curricular do estado de Mato Grosso do Sul, sendo: objetos que rolam e que não rolam (poliedros e corpos redondos), reconhecimento de formas (quadrado, triângulo, retângulo e círculo), classificação de figuras segundo o critério (triângulo, retângulo, círculo e quadrado), reconhecimento e relação das formas com objetos do meio físico e localização espacial: espaço corporal. 
VI Congresso Brasileiro de Informática na Educação (CBIE 2017)

Anais do XXVIII Simpósio Brasileiro de Informática na Educação (SBIE 2017)

\section{Geometrinho}

O jogo "Geometrinho" é tem a finalidade de mostrar a criança que a geometria está presente no dia a dia. A história do jogo se passa no trajeto da escola da personagem Maria até sua casa, com pequenos desafios pelo caminho. Os desafios acontecem na escola, no parque, no mercado, e outros locais, até que Maria consiga chegar no destino final, sua casa. O objetivo da criança é ajudar Maria a chegar à sua casa.

Todos os termos escritos no jogo utilizam letras maiúsculas pois, [Lima and Carvalho 2014] afirmam que muitas crianças na fase de alfabetização só reconhecem a palavra escrita com letra bastão. De acordo com [Kamii 1990], as crianças dessa faixa etária possuem ainda certa dificuldade de concentração, portanto se distraem facilmente. Sendo assim, todos os cenários do jogo foram pensados de modo a possuírem cores fortes e chamativas, porém com poucos elementos na tela.

Para ter acesso ao jogo, a criança deve ser cadastrada. O jogo é salvo e pode ser retomado do ponto onde parou. Para o cadastro a criança precisa: escolher um avatar, informar seu nome, nome do responsável, série e uma senha. A senha é composta por figuras geométricas: círculo, quadrado, triângulo e retângulo.

Há uma apresentação no jogo, onde Maria conta toda a sua história para a criança e como esta deverá ajudá-la retornar a sua casa. Há um mapa de desafios que apresenta os desafios do jogo e todo o percurso que o personagem deve realizar. Cada item do mapa mostrado na Figura 1 engloba 3 desafios de um conteúdo do Referencial Curricular e pode ser jogado em qualquer sequencia, sendo: 1- objetos que rolam e que não rolam; 2- reconhecimento de formas; 3- classificação de figuras; 4- reconhecimento e relação das formas com objetos do meio físico; 5- localização espacial: espaço corporal.

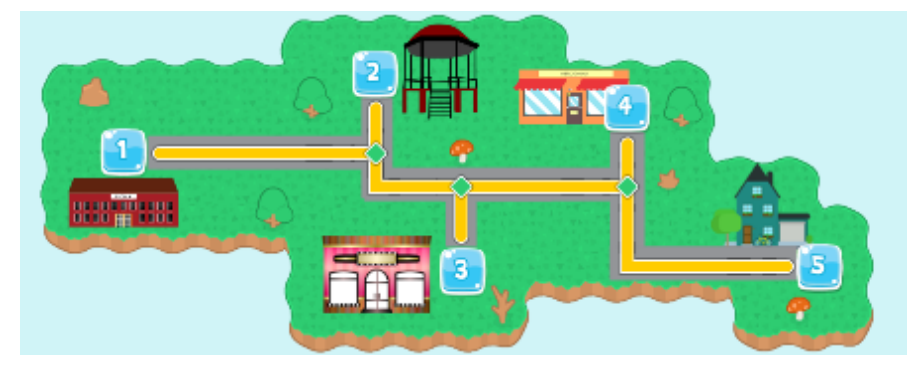

Figure 1. Mapa de desafios

Para o item 1 do mapa, os desafios envolvem identificar em uma lista de objetos quais rolam e quais não rolam. Como forma de apoio a decisão, ao clicar sobre cada objeto este se anima e gira em torno de si. No item 2, os desafios consistem em relacionar objetos com figuras geométricas semelhantes (Figura 2 parte 1) e encaixar as figuras geométricas na forma correspondente (Figura 2 parte 3 ).

Para o item 3 os desafios requerem relacionar a figura geométrica ao nome (Figura 2 parte 4) e selecionar figuras geométricas solicitadas. No item 4, os desafios envolvem localizar figuras geométricas em um cenário. E no item 5 os desafios incluem localizar objetos conforme sua posição no cenário (Figura 2 parte 2).

A apresentação dos desafios é feita por áudio e texto. Assim que selecionado, a personagem Maria aparece na parte inferior da tela contando a criança qual tarefa deve 
VI Congresso Brasileiro de Informática na Educação (CBIE 2017)

Anais do XXVIII Simpósio Brasileiro de Informática na Educação (SBIE 2017)
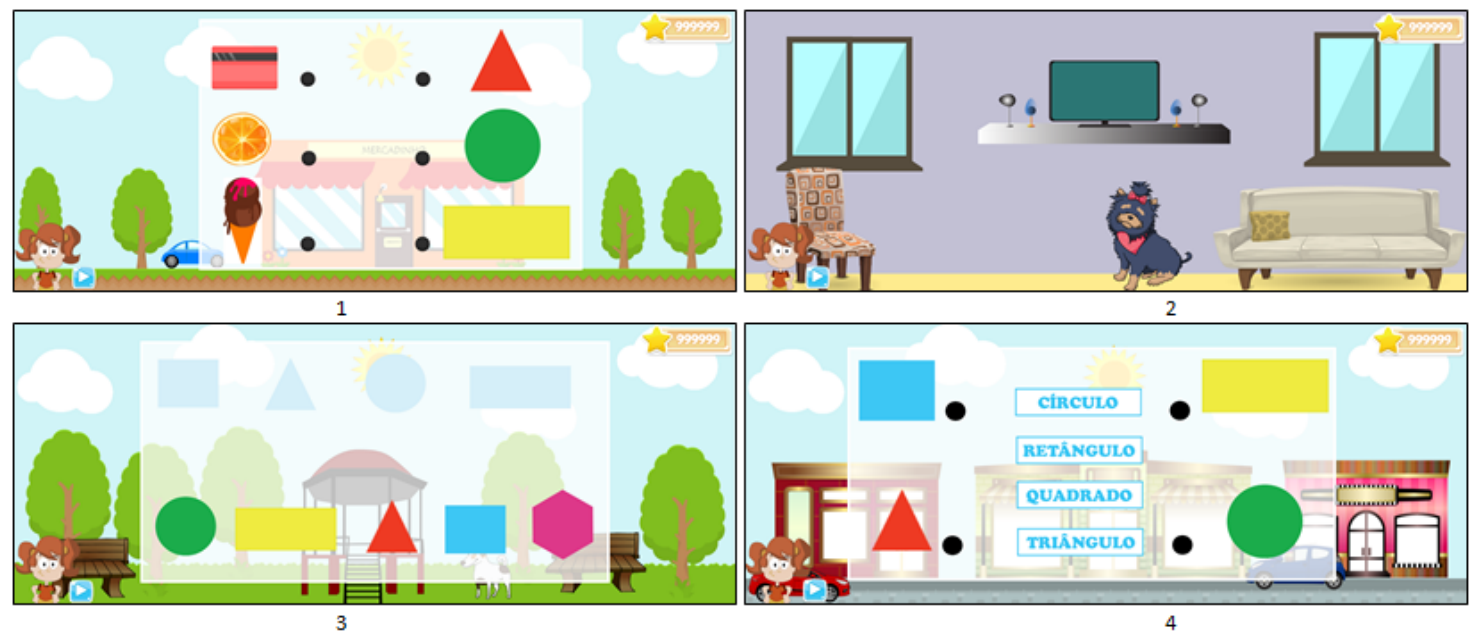

Figure 2. Exemplos de desafios do jogo

realizar para conseguir passar para a próxima etapa, seguido de uma revisão do conteúdo necessário. A personagem permanece no canto inferior da tela para que possa explicar o desafio novamente se necessário.

Para cada resposta correta dos desafios são somados 100 pontos, e para as respostas incorretas, um aviso aparecerá para a criança com a opção de tentar novamente. Ao final de cada desafio é exibida a quantidade de pontos adquiridos.

\section{Considerações Finais}

Neste artigo foi apresentada uma proposta de jogo educacional voltado ao ensino e aprendizagem da geometria, cujo principal objetivo é auxiliar o professor em sala de aula e mostrar ao aluno que a geometria está presente em seu dia a dia. Todos os desafios foram planejados e validados com o apoio de um profissional em educação matemática. Como trabalhos futuros têm-se a validação da adequabilidade do jogo no ensino e aprendizagem de geometria com professores e crianças do $1^{\circ}$ ano do ensino fundamental.

\section{References}

Bianchini, G., Gerhardt, T., and Dullius, M. M. (2010). Jogos no ensino da matematica quais as possiveis contribuicoes do uso de jogos no processo de ensino e de aprendizagem da matematica. Destaques Academicos.

Kamii, C. (1990). A crianca e o numero: implicacoes educacionais teoria de Piaget para a atuacao com escolares de 4 a 6 anos. Campinas, SP, 11 edition.

Lima, F. R. and Carvalho, M. A. F. d. (2014). Praticas pedagogicas de uma professora alfabetizadora e sondagem de hipoteses de escrita de uma crianca: cenas sociais letradas. Web-Revista SOCIODIALETO, 4.

Lorenzato, S. (1995). Por que nao ensinar geometria. A Educacao Matematica em Revista - SBEM.

Tarouco, L. M. R., Roland, L. C., Fabre, M.-C. J. M., and Konrath, M. L. P. (2004). Jogos educacionais. CINTED - UFRGS Novas Tecnologias na Educacao, 2. 